Bull. Mater. Sci., Vol. 22, No. 4, June 1999, pp. 751-755. (C) Indian Academy of Sciences.

\title{
Mössbauer and XRD studies on the effect of doping iron in $\mathrm{KCaY}\left(\mathrm{PO}_{4}\right)_{2}$
}

\author{
T N SAIRAM*, G V NARASIMHA RAO and B VISWANATHAN \\ Materials Science Division, Indira Gandhi Centre for Atomic Research, Kalpakkam 603 102, India
}

MS received 18 December 1998

\begin{abstract}
The effect of doping iron at the yttrium site in hexagonal $\mathrm{KCaY}\left(\mathrm{PO}_{4}\right)_{2}$ is studied for various concentrations of $x(0 \leq x \leq 1)$, of iron using Mössbauer and X-ray diffraction methods. For low iron concentrations, very little changes in structure are seen but at $x \approx 0 \cdot 1$, onset of new peaks in the XRD pattern is observed. The Mössbauer study of the doped samples reveals that iron has a solubility of up to $2.5 \%$ in the parent phase with any excess iron precipitating out to form a new and unknown phase. From a detailed analysis of the X-ray diffraction pattern (corresponding to $x=1$ ) of the latter phase, it is found that this phase is rhombohedral with the possible space group $R 3$.
\end{abstract}

Keywords. Mössbauer spectroscopy; X-ray powder analysis; crystal structure; Fe-substitution.

\section{Introduction}

Interest in double phosphates, with the general formula $\mathrm{ABLn}\left(\mathrm{PO}_{4}\right)_{2}(\mathrm{~A}=$ alkali, $\mathrm{B}=$ alkaline earths and $\mathrm{Ln}=$ rare earths), is increasing in recent times owing to their applications as phosphors and laser materials, when doped with active centres. These phosphates which are known to exist in three structures viz. hexagonal, tetragonal and monoclinic (Et-Tabirou and Daoudi 1980; Arthus et al 1991; Tie et al 1995a), are found to be structural analogues of the corresponding orthophosphates: $\mathrm{LnPO}_{4}$. Recently Tie et al (1995b) have reported the synthesis of a new hexagonal double phosphate, $\mathrm{KCaY}\left(\mathrm{PO}_{4}\right)_{2}$ which is isostructural with hexagonal $\mathrm{KNd}\left(\mathrm{PO}_{4}\right)_{2}$. Its space group is reported to be $P 6_{2} 22$ (Vlasse et al 1982). The structure is a three-dimensional network consisting of $\mathrm{Ln}-\mathrm{PO}_{4}-\mathrm{Ln}$ chains parallel to the $c$ axis. These chains are interconnected leaving large open channels, lined with oxygen atoms, running parallel to the $c$ axis. As early as in 1950, Mooney (1950) had pointed out that the open channels in the hexagonal $\mathrm{LnPO}_{4}$ could accommodate a neutral molecule of water. In the case of $\mathrm{KCaY}\left(\mathrm{PO}_{4}\right)_{2}$, the potassium atoms are found to occupy these channels instead of the zeolithic water. The calcium atoms, on the other hand, occupy the same sites as the rare earth ions which are eight-fold coordinated to oxygen atoms. As a result, Tie et al (1995b) expect disorders in the $\mathrm{K}^{+}$ and $\mathrm{Ca}^{2+}$ distributions leading to deviations in the site symmetries of the $\mathrm{PO}_{4}$ and $\mathrm{YO}_{8}$ polyhedra from $\mathrm{D}_{2}$ to $\mathrm{C}_{2}$. Using infrared and Raman spectral data of this compound they have been able to see this deviation in the symmetry.

*Author for correspondence
They have also investigated (Tie et al 1995c) the luminescent properties of $\mathrm{Eu}^{3+}-, \mathrm{Gd}^{3+}$ - and $\mathrm{Dy}^{3+}$-doped $\mathrm{KCaY}\left(\mathrm{PO}_{4}\right)_{2}$.

Since yttrium in $\mathrm{KCaY}\left(\mathrm{PO}_{4}\right)_{2}$ is eight-fold coordinated to oxygens, substitution of iron for yttrium is expected to bring about changes in structure as this high a coordination is somewhat unusual for iron, leading to a possible new phase. Hence we have doped various concentrations of iron and studied them using powder $X$-ray diffraction and Mössbauer spectroscopy. In this paper we report the results of the study on $\mathrm{KCaY}_{1-x} \mathrm{Fe}_{x}\left(\mathrm{PO}_{4}\right)_{2}$ for $x=0.01$, $0.05,0 \cdot 10,0.50$ and 1 .

\section{Experimental}

Both the doped and undoped samples of potassium calcium yttrium diphosphate were prepared by first mixing and grinding stoichiometric amounts of di-ammonium hydrogen phosphate, calcium carbonate, potassium carbonate and yttrium oxide along with ammonium chloride, which was used as a flux. This mixture was filled in a boat and heat treated at $573 \mathrm{~K}, 953 \mathrm{~K}$ and finally at $1293 \mathrm{~K}$ for a duration of $6 \mathrm{~h}$ each, with intermittent grinding of the reactants. The final product obtained was whitish, pale yellowish or dark reddish depending on whether the sample was undoped, partly doped or completely doped with iron. They were characterized by powder X-ray diffraction (XRD) technique. A Siemens D-500 powder diffractometer employing $\mathrm{CuK}_{\alpha}$ radiation was used for this purpose. The room temperature Mössbauer measurements were made on a home-made spectrometer (Chittaranjan et al 1993), working in the transmission geometry. The Mössbauer source was a $18 \mathrm{mCi}{ }^{57} \mathrm{Co}$ isotope 


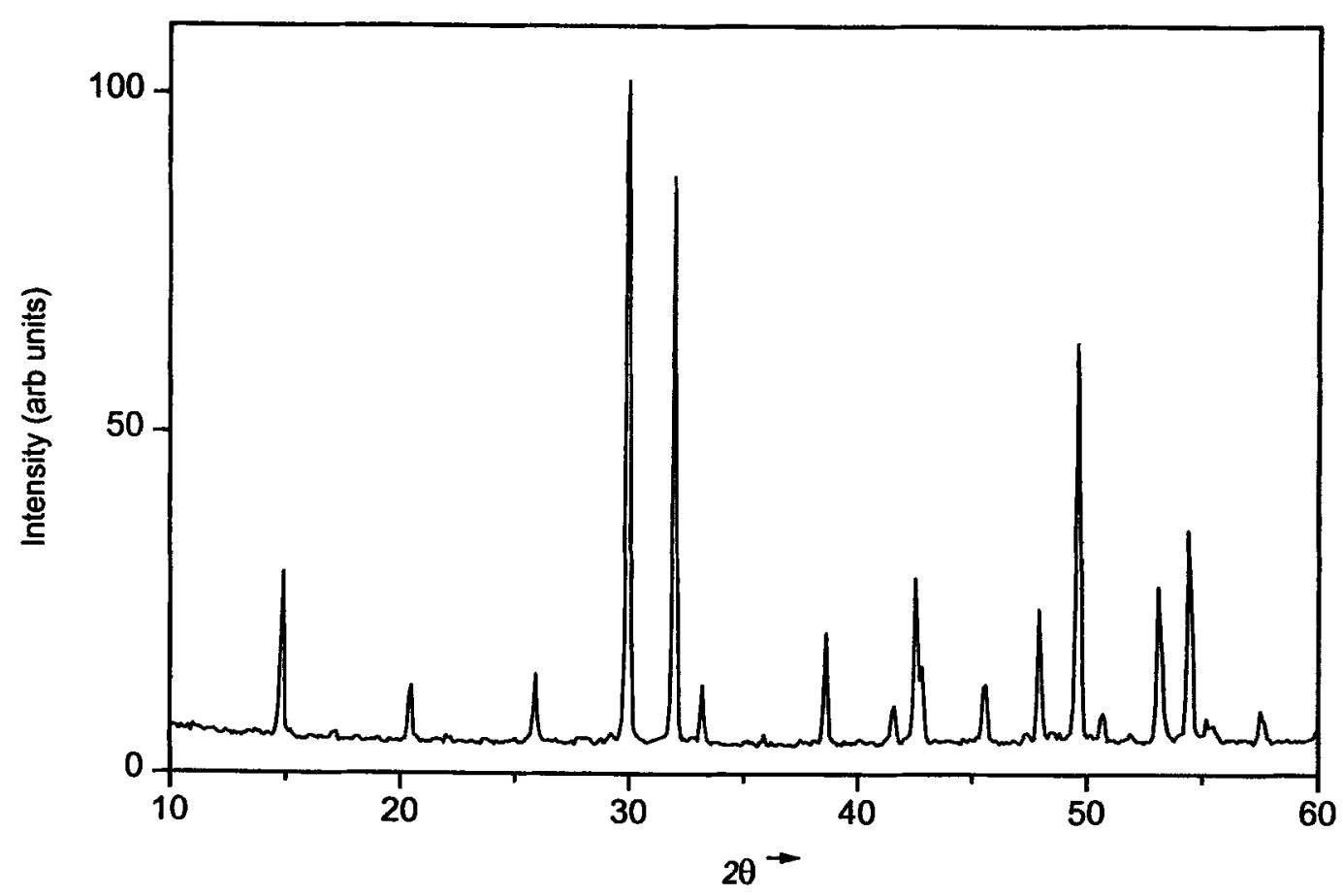

Figure 1. Powder X-ray diffraction pattern of as-prepared $\mathrm{KCaY}\left(\mathrm{PO}_{4}\right)_{2}$.

embedded in rhodium matrix. The spectrometer had an inherent linewidth of $0.23 \mathrm{~mm} / \mathrm{sec}$. Data analysis was done using a nonlinear least squares program based on the Levenberg-Marquardt method (Press et al 1988). The isomer shift values were reported with respect to $\alpha$-iron. Particle size distribution was determined with the help of 'Malvern Instruments' particle size analyzer.

\section{Results and discussion}

The X-ray diffraction pattern of the as-prepared $\mathrm{KCaY}\left(\mathrm{PO}_{4}\right)_{2}$ powder sample is shown in figure 1. The pattern is found to match well with the reported one (Tie et al 1995b). The lattice constants as determined from the experimental pattern are found to be $a=0.6886 \mathrm{~nm}$ and $c=0.6339 \mathrm{~nm}$. An interesting observation regarding the as-prepared doped samples was that they were found to be more compacted than the virgin sample which was powder-like. A preliminary check on the particle size indicated that for the $5 \%$ iron-substituted sample, about $18 \%$ of the particles are having a size of $<2 \mu$ and for the case of $10 \%$ iron, about $35 \%$ of the particles are below $2 \mu$ size. The particle size distribution in the case of $5 \%$ and $10 \%$ iron-doped samples are tabulated in table 1 .

In figure 2 are shown the XRD patterns of $1 \%$, $5 \%, 10 \%, 50 \%$ and $100 \%$ (figures $2 \mathrm{~b}-2 \mathrm{f}$, respectively) Fe-substituted samples of $\mathrm{KCaY}\left(\mathrm{PO}_{4}\right)_{2}$ along with that of the undoped sample (figure 2a). A comparison of these reveals the following interesting features: the XRD patterns of the $1 \%$ and $5 \%$ Fe-doped $\mathrm{KCaY}\left(\mathrm{PO}_{4}\right)_{2}$ show
Table 1. Particle size distribution in as-prepared $\mathrm{KCaY}_{1-x} \mathrm{Fe}_{x}\left(\mathrm{PO}_{4}\right)_{2}$.

\begin{tabular}{ccccc}
\hline$x=0.05$ & & \multicolumn{2}{c}{$x=0.10$} \\
\cline { 1 - 2 } \cline { 5 - 5 } Size $(\leq \mu \mathrm{m})$ & $(\%)$ & & Size $(\leq \mu \mathrm{m})$ & $(\%)$ \\
\hline 188.0 & 100 & & 13.2 & 100 \\
77.5 & 90 & & 9.8 & 92 \\
13.2 & 73 & & 7.3 & 74 \\
7.3 & 47.5 & & 4.7 & 49 \\
1.9 & 17.6 & & 1.9 & 35 \\
\hline
\end{tabular}

little changes (figures $2 \mathrm{~b}$ and $2 \mathrm{c}$ ) as compared to the undoped sample (figure $2 \mathrm{a}$ ) case. However, new peaks are seen to emerge at $\approx 11^{\circ}, 14^{\circ}, 26^{\circ}, 28^{\circ}, 31^{\circ}, 35^{\circ}$, etc in the pattern for $x=0 \cdot 1$. These peaks are seen to grow in intensity for higher iron content (figures $2 \mathrm{e}$ and $2 \mathrm{f}$ ). However, for $x=1$ case (figure $2 \mathrm{f}$ ) only the peaks corresponding to the newly formed phase are present. In order to find out whether the appearance of the new peaks is due to a structural phase transition possibly induced by doping of iron or not, a comparison of the peak positions in figure $2 \mathrm{a}$ with those of the corresponding peaks in figures $2 \mathrm{~d}$ and $2 \mathrm{e}$ was done. Very little shifts (maximum increase of about $0.05^{\circ}$ in $2 \theta$ ) were observed in the original peak positions which means that the appearance of the second phase is not due to any phase transformation. Thus it appears that the diffraction patterns of all the partiallydoped samples reflect mixed phase with peaks of both the parent and the new phase being present. The diffraction pattern corresponding to figure $2 \mathrm{f}$ does not fit to any of 


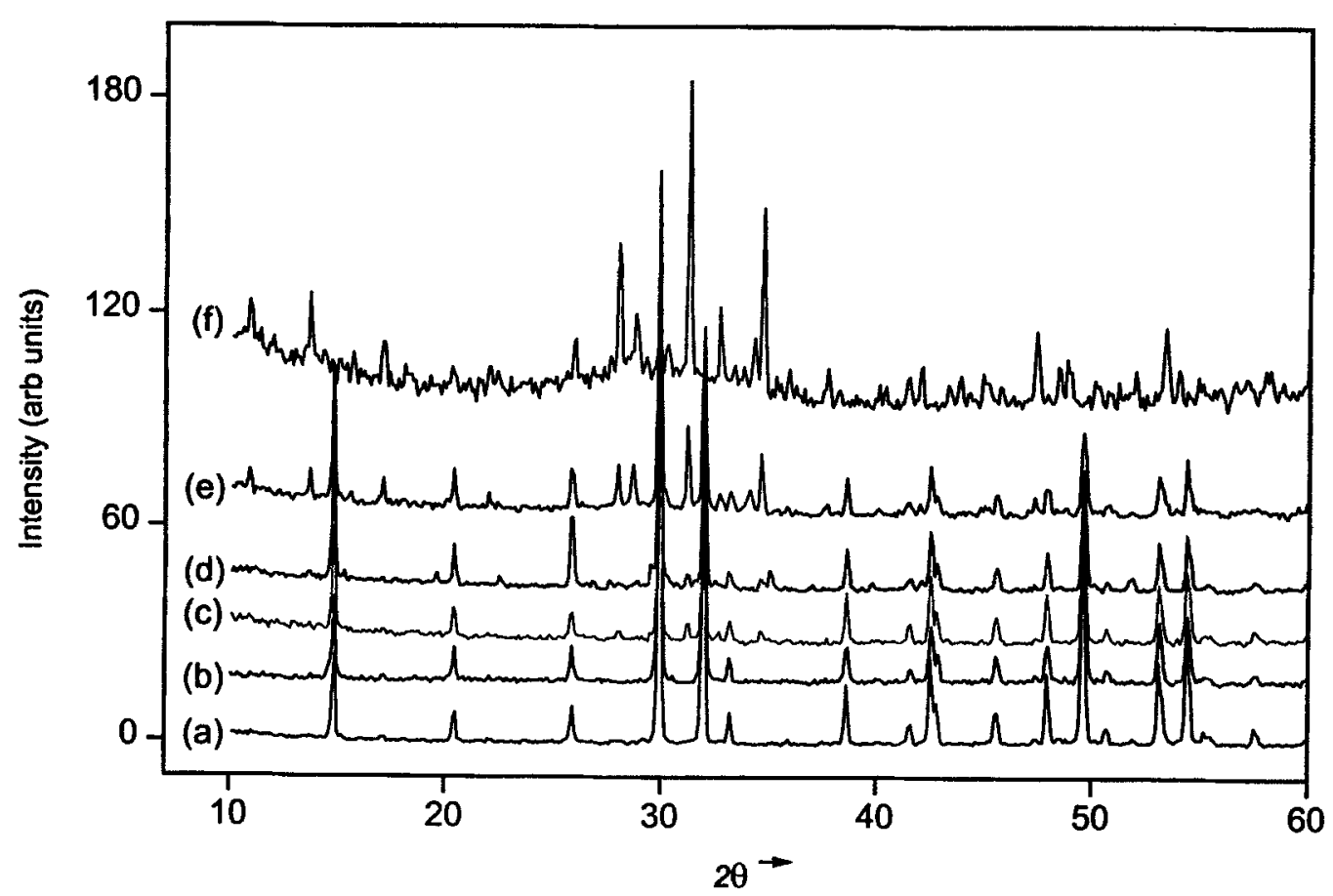

Figure 2. Powder $\mathrm{X}$-ray diffraction patterns of as-prepared $\mathrm{KCaY}\left(\mathrm{PO}_{4}\right)_{2}$ doped with (a) $0 \%$, (b) $1 \%$, (c) $5 \%$, (d) $10 \%$, (e) $50 \%$ and (f) $100 \%$ iron.

the known patterns but closely resembles that for $\mathrm{Ca}_{7} \mathrm{Mg}_{2} \mathrm{P}_{6} \mathrm{O}_{24}$ (JCPDS/ICDD Pattern No. 200348) (Ito 1968).

The pattern in figure $2 \mathrm{f}$ was initially fitted using TREOR (Werner 1964), a trial-and-error program for finding the approximate crystal system. The best fit obtained was for the hexagonal system having the following cell constants: $a=1.034 \mathrm{~nm}$ and $c=1.856 \mathrm{~nm}$ with a figure-of-merit of about 16 . With this information as a reference, the XRD pattern in figure $2 \mathrm{f}$ was next fitted systematically to each of the hexagonal and rhombohedral space groups, using the NBS-AIDS*83 least-square refinement program based on a routine by Appleman and Evans (1973). The best fit obtained was for the rhombohedral space group, $R 3$, with a fairly high figure-of-merit, $F=31$ with all the 44 lines getting indexed. The refined cell constants are: $a=1.0344 \pm$ $0.0001 \mathrm{~nm}$ and $c=1.8578 \pm 0.0004 \mathrm{~nm}$. Table 2 shows the fitted XRD data.

Figure 3 shows the Mössbauer spectra corresponding to the $5 \%, 10 \%, 50 \%$ and $100 \% \mathrm{Fe}$-doped samples of $\mathrm{KCaY}\left(\mathrm{PO}_{4}\right)_{2}$. Since the spectra are due to a mixture of the parent phase and a phase whose structure is not known, they were initially fitted with one doublet and later with two doublets, three doublets, etc. Of all the fits, only the two-doublet fit showed consistency in relation to the Mössbauer parameters (table 3). Another noteworthy feature was the observation of the following systematics: doublet 1 was common only to all the partially-doped samples while doublet 2 was common to all the spectra. As the magnitude of the peak shift in the XRD patterns of
Table 2. Fitted XRD data of the new phase.

\begin{tabular}{|c|c|c|c|c|c|c|c|}
\hline \multicolumn{8}{|c|}{ Space group: $R 3$} \\
\hline \multicolumn{4}{|c|}{$a=1.034 \mathrm{~nm}$} & \multicolumn{4}{|c|}{$c=1.856 \mathrm{~nm}$} \\
\hline $\begin{array}{l}d_{\mathrm{obs}} \\
(\AA)\end{array}$ & $h k l$ & $I / I_{0}$ & $\begin{array}{l}d_{\text {calc }} \\
(\AA)\end{array}$ & $\begin{array}{l}d_{\mathrm{Qbs}} \\
(\AA)\end{array}$ & $h k l$ & $I / I_{0}$ & $\begin{array}{l}d_{\text {catc }} \\
(\AA)\end{array}$ \\
\hline 8.096 & 101 & 39 & $8 \cdot 070$ & 2.858 & 205 & 100 & $2 \cdot 860$ \\
\hline 6.462 & 012 & 40 & 6.448 & 2.738 & 214 & 37 & 2.736 \\
\hline $5 \cdot 187$ & 110 & 25 & $5 \cdot 172$ & 2.685 & 303 & 20 & 2.689 \\
\hline 4.370 & 021 & 18 & $4 \cdot 354$ & 2.652 & 116 & 20 & 2.657 \\
\hline $4 \cdot 126$ & 104 & 15 & $4 \cdot 123$ & 2.585 & 220 & 64 & $2 \cdot 586$ \\
\hline 4.032 & 202 & 20 & 4.034 & 2.542 & 107 & 17 & 2.545 \\
\hline 3.970 & 113 & 18 & 3.970 & 2.502 & 125 & 19 & 2.503 \\
\hline 3.433 & 015 & 29 & 3.432 & 2.400 & 312 & 13 & 2.398 \\
\hline 3.329 & 211 & 20 & 3.331 & $2 \cdot 386$ & 223 & 19 & $2 \cdot 386$ \\
\hline 3.227 & 024 & 23 & $3 \cdot 224$ & $2 \cdot 148$ & 306 & 21 & $2 \cdot 149$ \\
\hline $3 \cdot 183$ & 122 & 56 & $3 \cdot 181$ & 1.918 & 045 & 30 & 1.918 \\
\hline 3.097 & 006 & 35 & 3.096 & 1.879 & 324 & 21 & 1.879 \\
\hline 2.988 & 300 & 29 & 2.986 & 1.865 & 413 & 24 & $1 \cdot 864$ \\
\hline
\end{tabular}

the partially-doped samples is not significant, and since a quadrupolar doublet is seen in all the Mössbauer spectra of the partially-doped samples, we infer that $\mathrm{Fe}$ has a slight solubility of less than $5 \%$ in $\mathrm{KCaY}\left(\mathrm{PO}_{4}\right)_{2}$ and that further addition of the dopant results in the precipitation of a second phase. These observations show that Mössbauer results are in agreement with the XRD results. The relative areas of doublets 1 and 2 of the partiallydoped samples are plotted in figure 4 . Since the ratio of the relative areas of doublet 1 to doublet 2 for $x=0.05$ is almost $50: 50$, we can immediately see that $2.5 \%$ of $\mathrm{Fe}$ 


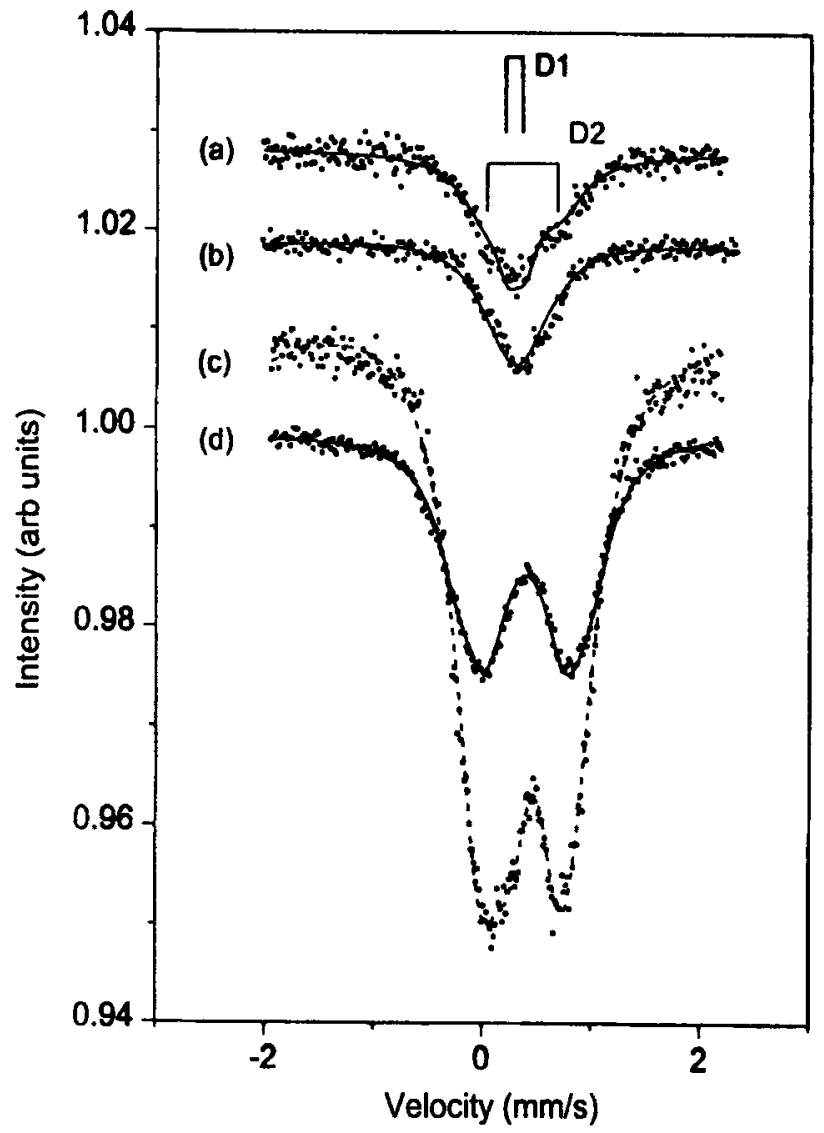

Figure 3. Mössbauer spectra at room temperature of asprepared $\mathrm{KCaY}\left(\mathrm{PO}_{4}\right)_{2}$ doped with (a) $5 \%$, (b) $10 \%$, (c) $50 \%$ and (d) $100 \%$ iron.

Table 3. Room temperature Mössbauer parameters of as-prepared $\mathrm{KCaY}\left(\mathrm{PO}_{4}\right)_{2}$ doped with (a) $5 \%$, (b) $10 \%$, (c) $50 \%$ and (d) $100 \%$ iron.

\begin{tabular}{|c|c|c|c|}
\hline$x$ & Parameters & Doublet 1 & Doublet 2 \\
\hline \multirow{4}{*}{0.05} & $\Gamma$ & $0 \cdot 24(1)$ & $0.55(2)$ \\
\hline & $\mathrm{C}$ & $0.31(2)$ & $0.37(2)$ \\
\hline & Q & $0.14(2)$ & $0.70(4)$ \\
\hline & A & 0.48 & 0.52 \\
\hline \multirow{4}{*}{$0 \cdot 1$} & $\Gamma$ & $0.23(1)$ & $0.56(2)$ \\
\hline & $\mathrm{C}$ & $0.35(3)$ & $0.38(2)$ \\
\hline & Q & $0.15(2)$ & $0.68(2)$ \\
\hline & A & 0.32 & 0.68 \\
\hline \multirow{4}{*}{0.5} & $\Gamma$ & $0.22(1)$ & $0.55(2)$ \\
\hline & C & $0.32(2)$ & $0.39(2)$ \\
\hline & $Q$ & $0 \cdot 16(2)$ & $0.68(2)$ \\
\hline & $A$ & 0.04 & 0.96 \\
\hline \multirow{4}{*}{1.0} & $\Gamma$ & $0.42(2)$ & $0.54(3)$ \\
\hline & $\mathrm{C}$ & $0.37(2)$ & $0.39(2)$ \\
\hline & Q & $1 \cdot 24(2)$ & $0.69(2)$ \\
\hline & A & 0.20 & 0.80 \\
\hline
\end{tabular}

$\Gamma$ : FWHM, C: Isomer shift (wrt $\alpha$-iron) in $\mathrm{mm} / \mathrm{s}$, Q: Quadrupolar splitting (mm/s), A: Area.

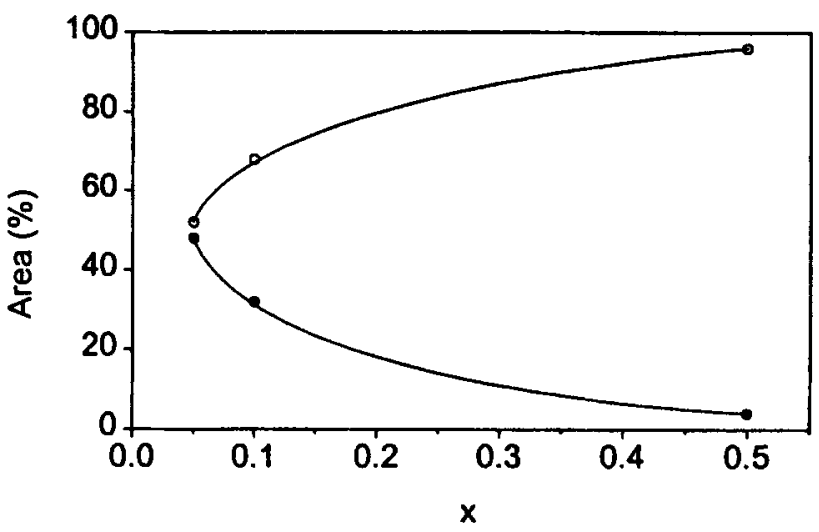

Figure 4. Relative areas of the doublet $1(\bullet)$ and doublet $2(0)$ for various concentrations of $\mathrm{Fe}$ in the Mössbauer spectra of the partially-doped samples of $\mathrm{KCaY}\left(\mathrm{PO}_{4}\right)_{2}$.

has substituted in the parent phase and the rest has formed the second phase. If this is indeed the case we should expect for the $x=0.1$ and 0.5 , relative area ratios of $25: 75$ and $5: 95$, respectively. From figure 4 we see that the area ratios for these two concentrations are close to what is expected. This close agreement in the area ratios between what is expected and what is observed substantiates the aforementioned picture.

From the isomer shift values of the two doublets it is seen that $\mathrm{Fe}$ exists in the $3+$ oxidation state in both the parent and the new phases. The small value of the quadrupolar splitting for doublet 1 means that the $\mathrm{Fe}$ environment in the parent compound is nearly cubic. Doublet 2 has a large quadrupolar splitting indicative of an asymmetric site for Fe with a distorted local structure in the new phase. The other doublet for $x=1$ sample is quite broad and we attribute it to the presence of an amorphous phase that may be due to some unreacted phases still being present. This corresponds to the slightly broad background seen in the XRD pattern in figure $2 f$.

From table 3 it is seen that the linewidth for doublet 2 corresponding to the new phase is fairly large. This broadening may be due to inhomogeneity of iron environments over the sample leading to a distribution of quadrupolar splittings. This seems unlikely in the present case as the XRD patterns in figures $2 c, 2 d$ and $2 \mathrm{e}$ do not show any broad background. The other reasons for line broadening are slow relaxation rates, low frequency thermal vibrations (Fluck 1966) and the presence of other cations in the second coordination sphere leading to differing environments around the iron atom, also called the next-nearest-neighbour effect (Russo et al 1996). Large linewidths, for instance, have been observed for Fe spectrum in the case of spinels (Russo et al 1996) and in $\mathrm{LnSr}_{2} \mathrm{Cu}_{2} \mathrm{Ga}_{(\mathrm{I}-x)} \mathrm{Fe}_{x} \mathrm{O}_{7}$ (Rykov et al 1994) where thermal vibrations of the Fe atom situated in a tetrahedral site are the cause. Since we do not know the complete crystal structure of this phase, it is difficult, at this stage, to pinpoint with definiteness the reason for the large linewidth. 


\section{Conclusions}

We have investigated a recently reported novel compound, $\mathrm{KCaY}\left(\mathrm{PO}_{4}\right)_{2}$ upon doping iron at the yttrium site to study its stability and local atomic structure by powder X-ray diffraction and Mössbauer spectroscopy.

From our results we have found that iron has a solubility of up to $2.5 \%$ in the hexagonal $\mathrm{KCaY}\left(\mathrm{PO}_{4}\right)_{2}$ but additional doping results in the precipitation of a second phase as shown by the Mössbauer and XRD results. Detailed analysis of the XRD data of this unknown phase has shown that it is rhombohedral with $R 3$ as its space group. Our Mössbauer data on this phase indicate that $\mathrm{Fe}$ occupies unique sites that are chemically equivalent.

\section{Acknowledgements}

The authors are thankful to Shri V S Sastry for valuable discussions and Dr G V Rama Rao for his help in particle size analysis. We also gratefully acknowledge $\mathrm{Dr}$ Baldev Raj and Dr C S Sundar for their constant encouragement.

\section{References}

Appleman D E and Evans Jr H T 1973 NTIS document No. PB216188, released by NTIS, 5285 Port Royal Road, Springfield, VA 22151

Arthus A, Duranceau C, Zambon D and Cousseins J C 1991 Eur. J. Solid State Inorg. Chem. 28499

Chittaranjan C M. Jayapandian J and Gopinathan K P 1993 Nucl. Instrum. \& Meth. B73 303

Et-Tabirou M and Daoudi A 1980 C. R. Acad. Sci. Paris, Ser. C 29193

Fluck E 1966 Adv. Inorg. Chem. \& Radiochem. 6462

Ito J 1968 J. Res. Natl. Bureau Stds A72 355

Mooney R C 1950 Acta Crystallogr. 3337

Press W H, Flannery B D, Tukolsky S A and Vetterling W T (eds) 1988 Numerical recipes, The art of scientific computing (Cambridge: Cambridge Univ. Press)

Russo U, Carbonin S and Giusta A D 1996 Mössbauer spectroscopy applied to magnetism and materials science (eds) G J Long and F Grandjean (New York: Plenum Press) vol. 2, p. 220

Rykov A, Caignaert V and Raveau B 1994 J. Solid State Chem. 109295

Tie S L, Su Q and Yu Y Q 1995a J. Solid State Chem. 114282

Tie S L, Su Q and Yu Y Q 1995b J. Alloys \& Compounds 2271

Tie S L, Su Q and Yu Y Q 1995c Phys. Status Solidi (a) 147267

Vlasse M, Bochu P, Parent C, Chaminade J P, Daoudi A, Le Flem G and Hagenmuller P 1982 Acta Crystallogr. B38 2328

Werner P 1964 Zeit. fur. Kristallogr. 120375 